\title{
QUALIDADE DA ÁGUA NAS SUB-BACIAS HIDROGRÁFICAS DOS RIOS CAPIVARI E MORTES, MINAS GERAIS
}

\author{
Water quality of the river sub-basin in Water Capivari and Mortes, Minas Gerais \\ Diego Vipa Amâncio ${ }^{1}$, Gilberto Coelho², Rosângela Francisca de Paula Vitor Marques ${ }^{3}$, Marcelo Ribeiro Viola ${ }^{4}$, \\ Carlos Rogério de Mello ${ }^{5}$

\begin{abstract}
${ }^{1}$ Doutorando em Recursos Hídricos em Sistemas Agrícolas - PPGRHSA, UFLA, e-mail: diegovipa@gmail.com 2 Professor Doutor, Departamento de Engenharia - DEG, UFLA, e-mail: coelho@deg.ufla.br

${ }_{3}^{3}$ Doutora em Recursos Hídricos em Sistemas Agrícolas - PPGRHSA, UFLA, e-mail: roeflorestal@hotmail.com

${ }^{4}$ Professor Doutor, Departamento de Engenharia - DEG, UFLA, e-mail: marcelo.viola@deg.ufla.br

${ }_{5}^{5}$ Professor Doutor, Departamento de Engenharia - DEG, UFLA, e-mail: crmello@deg.ufla.br
\end{abstract}

\section{Artigo enviado em 09/06/2017, aceito em 29/11/2017 e publicado em 10/04/2018.}

Resumo - Os recursos hídricos superficiais constituem-se na principal fonte hídrica, para múltiplos usos na região sul de Minas Gerais. Para tanto, em demandas como o abastecimento público, torna-se essencial o monitoramento da qualidade da água nos mananciais, visando a segurança hídrica e a minimização dos recursos dispendidos com tratamento de água. Objetivou-se avaliar o Índice de Estado Trófico (IET) e do Índice de Qualidade de Água (IQA) nas Unidades de Planejamento e Gestão de Recursos Hídricos (UPGRH) Alto Rio Grande (GD1) e Vertentes do Rio Grande (GD2). Foram amostrados três pontos no GD1 (PI - Rio Ingaí - Minduri, PII - Rio Capivari e PIII Rio Ingaí - Luminárias) e três pontos no GD2 (PIV - Rio das Mortes, PV - Rio do Peixe e PVI - Ribeirão dos Tabuões). O período de monitoramento foi entre abril de 2015 a fevereiro de 2016, totalizadas oito coletas. As variáveis avaliadas foram: $\mathrm{pH}, \mathrm{DBO}, \mathrm{OD}$, Coliformes Termotolerantes (CT), Turbidez, Sólidos Totais $(\mathrm{ST}), \mathrm{PO}_{4}{ }^{3-}, \mathrm{P}$, $\mathrm{NO}_{3}$ - e Temperatura. Calculou-se o IET e o IQA de acordo com a metodologia proposta por Lamparelli (2004) e Instituto Mineiro de Gestão das águas - IGAM (2005). Os cursos d’água monitorados ainda não foram enquadrados pelo órgão ambiental, assim considera-se a classe 2 como referência de qualidade para os trechos avaliados, classe essa destinada ao abastecimento para consumo humano, após tratamento convencional, conforme a DN COPAM CERH 01/08. Com base nos resultados, observou-se que os trechos avaliados foram classificados como Hipereutrófico, sinalizando excesso de nutrientes, fator associado às poluições difusas e pontuais próximas aos pontos de coleta. Em relação ao IQA, todos os pontos de monitoramento foram classificados como ruim, sendo o CT, o principal responsável pela piora do índice, estando associados à pecuária, lançamento de esgoto não tratado.

Palavras-chave: Índice de Estado trófico, índice de qualidade de água, poluições difusas e pontuais.

\begin{abstract}
The surface water resources are the main water source, for multiple uses in the southern region of Minas Gerais. Therefore, in demands such as public supply, it is essential to monitor the water quality in the water sources, aiming at water security and minimizing the resources spent with water treatment. The objective of this study was to evaluate the Trophic State Index (IET) and the Water Quality Index (IQA) in the Alto Rio Grande (GD1) and Rio Grande (GD2) Water Resources Planning and Management Units (UPGRH). Three points were sampled in the GD1 (PI - Rio Ingaí - Minduri, PII - Rio Capivari and PIII - Rio Ingaí - Luminárias) and three points in GD2 (PIV Rio das Mortes, PV - Rio do Peixe and PVI - Ribeirão dos Tabuões). The monitoring period was between April 2015 and February 2016, totaling eight collections. The variables evaluated were: $\mathrm{pH}, \mathrm{BOD}, \mathrm{OD}$, Thermotolerant coliforms (TC), Turbidity, Total Solids (TS), $\mathrm{PO}_{4}^{3-}, \mathrm{P}, \mathrm{NO}_{3-}$ and Temperature. The EIT and the IQA were calculated according to the methodology proposed by Lamparelli (2004) and IGAM (2005). The monitored watercourses have not yet been framed by the environmental agency, so class 2 is considered as quality reference for the evaluated stretches, a class that is destined to the supply for human consumption, after conventional treatment, according to DN COPAM CERH 01/08. Based on the results, it was observed that the evaluated sections were classified as Hyper-nutritious, signaling excess nutrients, factor associated to diffuse and point pollution near the points of collection. In relation to the IQA, the environmental conditions indicate that all the monitoring points were classified as their results would be in the bad class, with the TC being the main responsible for the worsening of the causal indexes, being associated to the cattle raising, untreated sewage .
\end{abstract}

Key words: Trophic State Index, water quality index, diffuse and punctual pollution. 


\section{INTRODUÇÃO}

A qualidade da água dos mananciais é resultante de fenômenos naturais e antrópicos, ou seja, em função do uso e ocupação dentro da bacia hidrográfica. Sobretudo, nas últimas décadas, as ações antrópicas, tanto dos centros urbanos quanto as atividades na zona rural têm contribuído para a degradação dos recursos hídricos. Dentre essas fontes, destaca-se o lançamento inadequado de efluentes (sanitários e industriais), sendo apontado como um dos principais responsáveis pelos impactos provados nos cursos d'água. Porém, sabe-se que a mineração e a agricultura, dentre outros, também podem contribuir para deterioração da qualidade da água, em função do escoamento superficial e carreamento para os cursos d'água.

Dentro dos nossos mananciais, as ações antrópicas oriundas de fontes difusas e pontuais, como a depleção dos níveis de oxigênio dissolvido (OD), maus odores, assoreamento da calha do rio, a proliferação de vetores de doenças de transmissão hídrica e a eutrofização, associada ao enriquecimento das águas com nitrogênio e fósforo, que pode vir causar excessiva proliferação de algas (LIMA et al, 2016). Com isso, a forma para mitigar os efeitos impactantes nos nossos cursos d'água, deve-se adotar medidas de controle, associadas a redução do lançamento, monitoramento e definição de variáveis de qualidade da água.

As legislações ambientais, de uma forma geral estabelecem regras para o lançamento de efluentes, com destaque para a Deliberação Normativa 01/2008 do Conselho Estadual de Política Ambiental do Estado de Minas Gerais (COPAM). Essa normativa visa classificar em classes ou definir metas de qualidade (enquadramento) dos cursos d'água, segundo os parâmetros físicos, químicos e biológicos determinados para as diversas variáveis. Por sua vez, o índice de estado trófico (IET), proposto por Lamparelli (2004), tem como principal característica classificar as águas superficiais em diferentes graus de trofia, ou seja, avaliar a concentração de nutrientes (fósforo), a associação com a turbidez (disco de Secci) ou a indicação da proliferação de algas (análise de clorofila) em determinado corpo hídrico. Já o Índice de Qualidade de Água (IQA) mais utilizado foi desenvolvido pela National Sanitation Foundation (NSF), localizada nos Estados Unidos. O IGAM, no estado de Minas Gerais adaptou o índice para as condições brasileiras
(ANDRADE et al., 2005; LOPES et al., 2008; SÁNCHEZ et al., 2007; FERREIRA et al., 2015).

Contudo, devido as condições e a necessidade de monitoramento das condições dos cursos d'água, objetivou-se neste trabalho: (i) avaliar a qualidade de água, utilizando o índice de estado trófico proposto por Lamparelli (2004); (ii) caracterizar os pontos avaliados segundo a classe de água atual, segundo os parâmetros estabelecidos na Deliberação Normativa Conselho Estadual de Política Ambiental do Conselho Estadual de Recursos Hídricos 01/08 e, (iii) avaliação do IQA de acordo com o método proposto pelo IGAM (2005) nas Unidades de Planejamento de Gestão de Recursos Hídricos do Alto Rio Grande (GD1) e Região Vertentes do Rio Grande (GD2).

\section{MATERIAL E MÉTODOS}

O presente trabalho foi realizado em subbacias hidrográfica dos Rios Capivari e Mortes, localizados na UPGRH - GD1 e GD2, como demonstrado na Figura. 1 e 2, respectivamente.

A primeira (apresentado na Tabela 1) tem relevo fortemente ondulado na região da cabeceira, com presença de Cambissolos e suave ondulado nas regiões baixas da UPGRH, onde há predominância de Latossolos e Argissolos, com altitudes variando entre 802 a $2.631 \mathrm{~m}$. Tem como vegetação predominante os Campos de Altitude, com fragmentos de Floresta Estacional Semidecidual e Floresta Ombrófila (MINAS GERAIS, 2008; SCOLFORO; CARVALHO, 2006).

Já na segunda sub-bacia do GD2 (Tabela 2), os solos predominantes são os latossolos. A medida que se aproxima da foz, os latossolos vermelhoamarelos distróficos, cambissolos e neossolos litólicos aparecem com maior frequência. Sua vegetação é composta principalmente de Mata Atlântica, Cerrado e Mata de Araucárias (MINAS GERAIS, 2008).

O clima da região, segundo a classificação climática de Köppen, é Cwa, temperado chuvoso (mesotérmico) com inverno seco e verão chuvoso, subtropical, com inverno seco e temperatura do mês mais quente maior que $22{ }^{\circ} \mathrm{C}$. As médias anuais de precipitação e a temperatura são de $1.470 \mathrm{~mm}$ e 19,2 ${ }^{\circ} \mathrm{C}$, respectivamente (DANTAS et al, 2007; ALMG, 2011; SILVA, 2014). 
Tabela 1. Pontos de amostragens e suas respectivas coordenadas.

\begin{tabular}{lcccc}
\hline \multirow{2}{*}{ Pontos } & \multicolumn{2}{c}{ Coordenadas } & Altitude (m) & Cursos D’Água \\
\cline { 2 - 4 } & Latitude & Longitude & & \\
$\mathrm{n}$ - I & $21^{\circ} 30^{\prime} 22.55^{\prime \prime S}$ & $44^{\circ} 54^{\prime} 56.84^{\prime \prime} \mathrm{O}$ & 995 & Ingaí - Minduri \\
$\mathrm{P}$ - II & $21^{\circ} 28^{\prime} 40.69^{\prime \prime S}$ & $44^{\circ} 45^{\prime} 57.26^{\prime \prime} \mathrm{O}$ & 863 & Capivari \\
$\mathrm{P}$ - III & $21^{\circ} 30^{\prime} 22.76^{\prime \prime} \mathrm{S}$ & $44^{\circ} 54^{\prime} 56.59^{\prime \prime} \mathrm{O}$ & 898 & Ingaí - Luminárias \\
\hline
\end{tabular}

Tabela 2. Pontos de amostragens e suas respectivas coordenadas.

\begin{tabular}{lcccc}
\hline \multirow{2}{*}{ Pontos } & \multicolumn{2}{c}{ Coordenadas } & Altitude (m) & Cursos D'Água \\
\cline { 2 - 5 } & Latitude & Longitude & \\
$\mathrm{P}-\mathrm{IV}$ & $21^{\circ} 3^{\prime} 44.31^{\prime \prime S}$ & $44^{\circ} 18^{\prime} 41.93 " \mathrm{O}$ & 868 & Mortes \\
$\mathrm{P}-\mathrm{V}$ & $21^{\circ} 03^{\prime} 38.86^{\prime \prime} \mathrm{S}$ & $44^{\circ} 29^{\prime} 57.38^{\prime \prime} \mathrm{O}$ & 878 & Peixe \\
$\mathrm{P}-\mathrm{VI}$ & $21^{\circ} 4^{\prime} 49.61^{\prime \prime S}$ & $44^{\circ} 42^{\prime} 8.63^{\prime \prime} \mathrm{O}$ & 864 & Rib. Dos Tabuões \\
\hline
\end{tabular}

O período de monitoramento foi de abril de 2015 a fevereiro de 2016, totalizando oito campanhas, de forma a abranger o período seco e chuvoso, sendo que nas épocas de estiagem, as coletas foram feitas bimestralmente, e no período chuvoso mensalmente. No ponto $\mathrm{P}-\mathrm{V}$ (Rio do Peixe) foram feitas sete campanhas, em razão do monitoramento ter começado antes.

Foram coletadas amostras integradas em três verticais ao longo de cada seção monitorada, com amostragens nas margens e no centro da calha do rio, de acordo com a NBR 9897/1997. Utilizou-se para a coleta de água um Amostrador de Sedimentos em Suspensão DH - 49 em movimentos fixos em cerca de $30 \mathrm{~cm}$ de profundidade. Os procedimentos de coleta e preservação das amostras obedeceram às normas estabelecidas pela Companhia Ambiental do Estado de São Paulo - CETESB (2011). O Oxigênio Dissolvido foi fixado em campo, pois, a distância percorrida durante a campanha de monitoramento é longa e, assim, a preservação da amostra é essencial. Com esse propósito, foram utilizados os reagentes Iodeto de Azida e Sulfato Manganoso.

As análises laboratoriais para o IET e IQA foram realizadas no Núcleo de Engenharia Ambiental e Sanitária da Universidade Federal de Lavras (UFLA), no Laboratório de Análise de Qualidade de Água, seguindo as normas regulamentadas de acordo com (APHA, 2012).

Durante a etapa de monitoramento, a medição da temperatura nos cursos d'água foi realizada concomitantemente às medições de vazão. Para tal finalidade foi utilizado um termômetro digital.

\section{Determinação do Índice de Estado Trófico}

Calculou-se o índice de estado trófico seguindo a metodologia proposta por Lamparelli (2004), a partir dos valores de fósforo total, que devem ser entendidos por uma medida do potencial de eutrofização, sendo que este atua como agente no processo. O cálculo de IET para rios, é dado pela Equação 1:

$I E T_{L}=10 \cdot\left[6-\frac{1,77-0,42 \cdot \ln (P T)}{\ln 2}\right] 20$

Em que:

$\mathrm{IET}_{\mathrm{L}}=$ Índice de Estado Trófico (proposto por Lamparelli, 2004);

$\mathrm{PT}=$ Fósforo Total $\left(\mu \mathrm{g} \mathrm{L} \mathrm{L}^{-1}\right)$.

Os valores obtidos pelas equações anteriores são interpretados a um nível de ponderação, determinados na Tabela 3 a seguir.

Tabela 3. Valores dos limites de concentrações de Fósforo Total para os diferentes níveis tróficos.

\begin{tabular}{lc}
\hline Classes & Valor \\
\hline Ultraoligotrófico & $=47$ \\
Oligotrófico & $47<$ IET $\leq 52$ \\
Mesotrófico & $52<$ IET $\leq 59$ \\
Eutrófico & $59<$ IET $\leq 63$ \\
Supereutrófico & $63<$ IET $\leq 67$ \\
Hipereutrófico & $>67$ \\
\hline Fonte: Lamparelli (2004). &
\end{tabular}




\section{Variáveis de Qualidade de Água}

As Deliberações Normativas Conjuntas COPAM CERH 01/08 dispõe sobre a classificação dos corpos d'água e diretrizes ambientais junto ao seu enquadramento, bem como estabelece as condições e padrões de lançamento de efluentes e dá outras providências para o destino final das águas, conforme o enquadramento.

O Art. $4^{\circ}$ (Seção 1) mostra que as águas doces de âmbito estadual (por órgãos ambientais), podem ser classificadas como limite aceitável ao abastecimento para consumo humano como classe 2 .

O IQA é calculado de acordo com a equação 2 descrita a seguir:

$\mathrm{IQA}=\prod_{\mathrm{i}=0}^{9} \mathrm{q}_{\mathrm{i}}{ }^{{ }^{\mathrm{w}} \mathrm{i}}$

Em que:

IQA - índice de qualidade da água, um número de 0 a 100; qi é a qualidade da variável i obtido por meio da curva média específica de qualidade; wi é o peso atribuído à variável, em função de sua importância na qualidade (entre 0 e 1 ).

\section{Determinação do Índice de Qualidade de Água}

Para a determinação do IQA utilizou-se a metodologia do IGAM, na qual leva em conta um conjunto de nove variáveis consideradas mais representativas para a caracterização da qualidade de água. Essas variáveis e seus respectivos pesos, de acordo com sua importância relativa no cálculo do IQA, estão apresentados na Tabela 4.

$\mathrm{Na}$ Tabela 5 pode-se verificar a classificação da qualidade da água conforme os valores de IQA. Os cursos d'água monitorados ainda não foram enquadrados pelo órgão ambiental, assim, considerase a classe 2 como referência de qualidade a ser alcançada, classe essa destinada ao abastecimento para consumo humano, após tratamento convencional, conforme a DN COPAM CERH 01/08 - para águas doces.

Tabela 4. Peso das variáveis para o cálculo do IQA

\begin{tabular}{lc}
\hline Variável & Peso - wi \\
\hline Oxigênio Dissolvido (\% OD) & 0,17 \\
Col. Termotolerantes (NMP/100 mL) & 0,15 \\
$\mathrm{pH}$ & 0,12 \\
$\mathrm{DBO}\left(\mathrm{mg} \cdot \mathrm{L}^{-1}\right)$ & 0,10 \\
Nitratos (mg.L $\left.{ }^{-1} \mathrm{NO}_{3}\right)$ & 0,10 \\
Fosfatos (mg/L-1 $\left.\mathrm{PO}_{4}^{3-}\right)$ & 0,10 \\
Variação na Temperatura $\left({ }^{\circ} \mathrm{C}\right)$ & 0,10 \\
Turbidez (UNT) & 0,08 \\
Resíduos Totais $\left(\mathrm{mg}^{3} \mathrm{~L}^{-1}\right)$ & 0,08 \\
\hline
\end{tabular}

Fonte: Instituto Mineiro das Águas, IGAM (2005).

Tabela 5. Nível de qualidade da água

\begin{tabular}{lc}
\hline Nível de qualidade & Faixa \\
\hline Excelente & $90<$ IQA $=100$ \\
Bom & $70<$ IQA $<90$ \\
Médio & $50<$ IQA $<70$ \\
Ruim & $25<$ IQA $<50$ \\
Muito ruim & $0<$ IQA $<50$ \\
\hline
\end{tabular}

Fonte: Instituto Mineiro das Águas, IGAM (2005).

\section{RESULTADOS E DISCUSSÃO}

\section{Índice de Estado Trófico}

Como mostra a Tabela 6, no P - I (Ingaí Minduri) os graus de trofia foram Eutrófico,
Hipereutrófico e Mesotrófico. Em uma das campanhas realizadas no período chuvoso (sexta campanha), o ponto foi classificado como Mesotrófico e, apontando uma baixa carga de nutrientes em níveis aceitáveis. No período de estiagem e no período chuvoso o seu resultado médio do IET foi Hipereutrófico, podendo 
inferir que a com excesso de nutrientes no ponto monitorado, e como classificação geral, o mesmo grau de trofia, sendo que, as atividades antrópicas apresentaram grande participação interferindo nas concentrações de matéria orgânica, afetando significativamente seus múltiplos usos.

Já no P - II, foram observadas três classificações, Hipertrófico, Eutrófico e Supereutrófico, sendo que o IET médio durante o período apontou uma condição Hipereutrófico. Dessa forma, atribui-se a deterioração da qualidade da água às ações antrópicas ocorridas no entorno da bacia, ou em menor escala, de fontes naturais, o que é corroborado por Fia et al (2009). Segundo os autores, elevados teores de fósforo ocorrem entorno da bacia devido à presença de regiões que apresentam intensa atividade agrícola.

Importante destacar que a seção de controle P - III teve como classificação média supereutrófico, classificação abaixo dos pontos P - I e P - II. Com isso, supõe-se que a chuva pode ter contribuído para a diluição da concentração de $\mathrm{P}$ na seção, e que, as contribuições de fontes difusas (drenagem de áreas agrícolas e com criação extensiva de animais) existem, porém, são menos importantes que nos outros dois pontos amostrados. Durante o monitoramento, os resultados finais de IET indicaram que a qualidade dos cursos d'água estão associados à poluição ao longo da bacia nos seus três pontos amostrais e ao regime pluviométrico. Assim sendo, o grau de trofia médio foi, respectivamente, de Hipereutrófico e Supereutrófico, nos períodos secos e chuvosos.

De acordo com a Tabela 7, o P - IV (Rio das Mortes) apresentou graus de trofia classificados como Eutrófico, Hipereutrófico e Supereutrófico. Na terceira campanha, o resultado Eutrófico, corresponde à época coletada com grandes atividades antrópicas, como exploração mineral, determinando as alterações indesejáveis no meio, como excesso de nutrientes e interferência em seus múltiplos usos. Ressalta-se que tanto para o período seco como chuvoso a classificação média em cada período foi hipereutrófico, evidenciando, no geral, alto grau de poluição no referido ponto amostral, o qual é afetado por grandes quantidades de matéria orgânica e nutrientes, que, por sua vez influencia na vida aquática.

O P - V (Rio do Peixe), teve como classificações Eutrófico e Hipereutrófico e sua média final como Supereutrófico. O uso e ocupação do solo da região é predominantemente pastagem e atividade agropecuária extensiva, o que justifica os resultados obtidos. Nas últimas campanhas o grau de trofia enquadrou para elas, devido ao assoreamento. A classificação no período seco foi hipereutrófico e no período chuvoso supereutrófico indicando que o período chuvoso, com maior vazão foi fator de mudança do IET, indicando efeito de sazonalidade.

O IET do P - VI (Ribeirão dos Tabuões), foi classificado como hipereutrófico, não apresentando influência da sazonalidade. Este curso d'água é caracterizado por elevado grau de assoreamento, sendo mínima a mata ciliar em um dos lados do curso d'água. Seus valores estão associados as atividades no entorno da bacia, como pecuária e plantações.

Tabela 6. IET em função dos períodos de estiagem e chuvoso na sub-bacia Capivari

\begin{tabular}{|c|c|c|c|c|c|c|c|}
\hline & \multirow{3}{*}{$\begin{array}{c}\text { Data das } \\
\text { Campanhas }\end{array}$} & \multicolumn{6}{|c|}{ IET (Capivari) } \\
\hline & & \multicolumn{2}{|c|}{$\mathrm{P}-\mathrm{I}$} & \multicolumn{2}{|c|}{$\mathrm{P}-\mathrm{II}$} & \multicolumn{2}{|c|}{$\mathrm{P}-\mathrm{III}$} \\
\hline & & Valor & Classe & Valor & Classe & Valor & Classe \\
\hline & $10 / 04 / 15$ & 77,38 & Hiper. & 75,74 & Hiper. & 65,07 & Super. \\
\hline Período & $29 / 07 / 15$ & 59,22 & Eutro. & 59,94 & Eutro. & 67,28 & Hiper. \\
\hline \multirow[t]{4}{*}{ Seco } & $22 / 09 / 15$ & 71,59 & Hiper. & 70,74 & Hiper. & 69,82 & Hiper. \\
\hline & Classificação & 69,39 & Hiper & 68,80 & Hiper & 67,39 & Hiper \\
\hline & $26 / 10 / 15$ & 62,53 & Eutro. & 67,28 & Hiper. & 67,75 & Hiper. \\
\hline & $23 / 11 / 15$ & 71,29 & Hiper & 71,52 & Hiper. & 70,82 & Hiper. \\
\hline Período & $18 / 12 / 15$ & 58,38 & Meso. & 70,74 & Hiper. & 57,39 & Meso. \\
\hline \multirow[t]{5}{*}{ Chuvoso } & $22 / 01 / 16$ & 82,30 & Hiper & 63,95 & Super. & 65,31 & Super. \\
\hline & $19 / 02 / 16$ & 79,31 & Hiper & 69,92 & Hiper. & 56,15 & Meso. \\
\hline & Classificação & 70,76 & Hiper & 68,68 & Hiper & 63,48 & Super \\
\hline & Média Final & \multicolumn{2}{|c|}{70,25630} & \multicolumn{2}{|c|}{68,73295} & \multicolumn{2}{|c|}{64,95293} \\
\hline & $\begin{array}{c}\text { Classificação } \\
\text { Final }\end{array}$ & \multicolumn{2}{|c|}{ Hipereutrófico } & \multicolumn{2}{|c|}{ Hipereutrófico } & \multicolumn{2}{|c|}{ Supereutrófico } \\
\hline
\end{tabular}


Tabela 7. IET em função dos períodos de estiagem e chuvoso na sub-bacia Mortes.

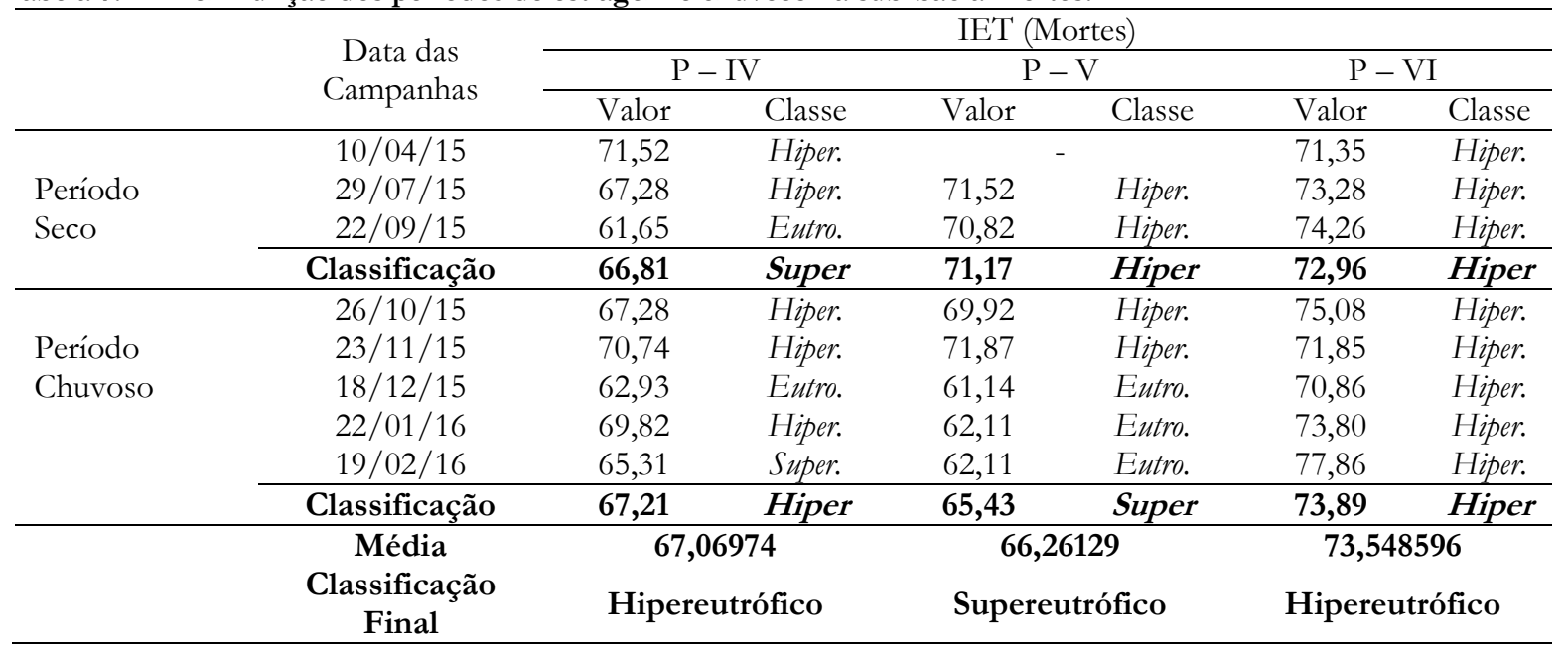

\section{Variáveis da Qualidade de Água}

\section{Sub-bacia Hidrográfica Alto Rio Grande (GD1) Vertentes do Rio Grande (GD2)}

$\mathrm{Na}$ tabela 8, observa-se nos três pontos amostrais na sub-bacia do GD1 os valores de coliformes termotolerantes variaram durante $\mathrm{o}$ período de monitoramento. Em épocas de estiagem, seus valores se apresentaram de forma geral, menores do que no período chuvoso, porém, em comparação com a DN COPAM CERH 01/08 nenhuma amostra se apresentou dentro dos padrões estabelecidos. Observou-se que no período chuvoso seus valores aumentaram, podendo inferir que foi devido ao carreamento das fezes de animais por meio do escoamento superficial, haja vista que há predomínio de agropecuária nas sub-bacias em questão.

A DBO, variável que indica a quantidade de oxigênio necessário para biodegradar a matéria orgânica, não excedeu o limite estabelecido durante todo o monitoramento dos trechos. Vale ressaltar que quanto maiores os valores de $\mathrm{DBO}$, mais rapidamente o oxigênio dissolvido irá reduzir e comprometer a vida aquática. No P - II e P - III notou-se valores no limite do valor máximo permitido (VMP) que é de 5,0 mg. $\mathrm{L}^{-1}$ (enquadramento na Classe 2) isso mostra que, apesar de estar em período de poucas chuvas, o contato dos bovinos no entorno da bacia e o uso e ocupação do solo na região, que é praticamente de pastagem, foram fatores determinantes do comportamento da DBO.

A concentração de $\mathrm{PO}_{4}^{3-}$ excedeu o limite estabelecido para a classe $2 \mathrm{em}$ apenas um dia de coleta, o qual foi encontrado na primeira campanha na seção de controle do P - III com resultado de $0,233 \mathrm{mg}$. $\mathrm{L}^{-1}$. As demais campanhas nos três pontos amostrais se mostraram dentro dos padrões estabelecidos, não ultrapassando o limite permitido.

$\mathrm{O}$ pH também ficou dentro dos padrões estabelecidos, sendo que seu maior valor foi 8,46 , ocorrido na quinta campanha no $\mathrm{P}$ - I. O pH manteve-se dentro do padrão aceitável, entre 6 e 9. No período de chuvas o $\mathrm{pH}$, em algumas campanhas, registrou valores acima de 8,0. Os valores de $\mathrm{pH}$ estão relacionados a fatores naturais, como dissolução de rochas, absorção de gases atmosféricos, oxidação da matéria orgânica e fotossíntese, e a fatores antropogênicos, como por exemplo, o despejo de esgotos domésticos e industriais, e a consequente oxidação da matéria orgânica (LOPES, 2010; VON SPERLING, 2014).

A concentração de oxigênio dissolvido ficou dentro dos padrões estabelecidos nos três pontos amostrais, ou seja, foi sempre maior que 5,0 mg. $\mathrm{L}^{-1}$. No P - I ao longo do período de avaliação, o ele apresentou certa variação, sendo o valor máximo encontrado igual a $8,0 \mathrm{mg}$. $\mathrm{L}^{-1}$ (sétima campanha). Pinto et al (2009), relataram em estudo sobre a qualidade de água do Ribeirão Lavrinha na região do Alto Rio Grande, que quando a temperatura da água se apresentava baixa, altas concentrações de oxigênio dissolvido foram encontradas, e a matéria orgânica também registrou valores baixos.

Os valores de Sólidos Totais apresentaramse acima do permitido na quinta e oitava campanhas no ponto amostral Ingaí - Luminárias. Esse valor registrado se deve ao fato de que na região ocorreram chuvas intensas, determinando a quantidade alta de 
Sólidos Totais. Poleto e Carvalho (2004) também encontraram valores altos de sólidos totais em torno de $700 \mathrm{mg}$. $\mathrm{L}^{-1}$ na microbacia do córrego do Ipê, em São Paulo, na época chuvosa. No entorno dessa microbacia havia solo exposto e monoculturas, sendo observado carreamento de partículas em época chuvosa para o curso d'água. Contaminantes da água, de forma geral, contribuem para a carga de sólidos, os quais podem ser classificados pelas suas características físicas e químicas.

A temperatura da água em todo monitoramento variou de 15,60 a $23,50{ }^{\circ} \mathrm{C}$ para os três pontos amostrais.

A variável turbidez sofreu influência da sazonalidade nos três pontos amostrais, apresentando valores acima do permitido durante o período de chuvas. Seus altos valores podem estar associados ao carreamento de partículas de solo, despejos incorretos de efluentes gerados a partir de esgotos e a presença de animais nas margens do curso d'água monitorado.

Os valores registrados de $\mathrm{NO}_{3}^{-}$estiveram acima do permitido apenas no $\mathrm{P}$ - II na primeira campanha. Marques et al. (2011) relataram, que valores acima do permitido em cursos d'agua estão associados a dejetos humanos e animais. Não só na primeira campanha, mas os altos teores de nitrato em cursos d'água possuem efeitos diversos na saúde. A intensidade do processo de contaminação depende, principalmente, das quantidades de nitrato ali presentes ou adicionadas ao solo, da permeabilidade do solo, das condições climáticas e o manejo de irrigação e da profundidade do lençol freático ou aquífero (EMBRAPA, 2002).

Observa-se pela Tabela 9, que para os coliformes termotolerantes, os resultados foram maiores que o permitido pela DN COPAM CERH 01/2008. Com exceção do P - IV, foi observado aumento de coliformes no período chuvoso. Seus altos valores são associados ao escoamento superficial direto da região de cabeceira, com grandes quantidades de dejetos, tanto animais quanto humanos.

Já a concentração de DBO esteve dentro dos limites estabelecidos para os três pontos amostrais. $\mathrm{Na}$ terceira campanha do $\mathrm{P}-\mathrm{V}$ foi encontrado um resultado no limite máximo permitido, indicando fonte de poluição por matéria orgânica a montante.

A medição da concentração de fosfato indicou valores acima do permitido em duas campanhas do P - IV, durante o período seco, podendo estar correlacionado à poluição difusa, muito provavelmente por fertilizantes aplicados na agricultura. Os nutrientes em excesso tendem a escoar superficialmente pelo terreno, até atingir os corpos d'água. Nos outros pontos amostrais o valor de Fosfato esteve dentro do padrão estabelecido.

$\mathrm{O} \mathrm{pH}$ nos três pontos amostrais variou de 6,66 a 8,29 durante o monitoramento, estando dentro do padrão estabelecido que é de 6,0 a 9,0. O maior valor encontrado pode ser explicado pela alta temperatura registrada na mesma campanha, que foi de $27,2^{\circ} \mathrm{C}$.

Os valores de oxigênio dissolvido ficaram dentro dos padrões estabelecidos durante $\mathrm{O}$ monitoramento, o menor valor registrado foi $6,5 \mathrm{mg}$. $\mathrm{L}^{-1}$ no $\mathrm{P}-\mathrm{VI}$ e o maior de $8,8 \mathrm{mg}$. $\mathrm{L}^{-1}$ no $\mathrm{P}-\mathrm{IV}$. O seu maior valor de OD registrado, deve-se ao fato que as concentrações de matéria orgânica foram mais baixas.

Os valores registrados Sólidos totais na sexta campanha foram maiores que estabelecido para a classe 2, para ambos os pontos amostrais. O resultado pode estar associado às fortes chuvas ocorridas em dias anteriores à coleta. Observou-se também que as maiores concentrações de sólidos totais se deram no período chuvoso, situação que está em conformidade com os altos valores registrados de turbidez, que por sua vez, apresentou valores acima do permitido, no período chuvoso, em todos os pontos amostrais.

O nitrato, por outro lado, esteve com concentrações acima do permitido apenas na segunda campanha do P - VI. Seus altos valores podem estar associados ao processo de lixiviação de fertilizantes usados na agricultura e ao transporte de sedimentos pelo escoamento superficial direto.

\section{Índice de Qualidade de Água}

\section{Sub-bacia hidrográfica Alto Rio Grande (GD1) Vertentes do Rio Grande (GD2)}

Apresenta-se, na Figura 3, os valores de IQA calculado para os pontos amostrais localizados na sub-bacia Hidrográfica Capivari. Para a sub-bacia P I observou-se que no período seco, o IQA apresentou classificação Média, devido ao reduzido índice pluviométrico. Esta situação ocorreu devido ao fato que os parâmetros que mais contribuíram para sua classificação foram as menores concentrações de coliformes, turbidez e sólidos totais, em comparação com o período chuvoso. Durante o monitoramento, a melhor classificação foi registrada na terceira campanha $(\mathrm{IQA}=53,48)$. Fato que pode ser atribuído ao menor carreamento de sedimentos, 
despejos incorretos de efluentes. Por outro lado, o menor IQA $(40,15)$, classificado como Ruim, foi obtido na última campanha, o que está associado às altas concentrações de coliformes, sólidos totais, turbidez e nitrato. No período chuvoso a qualidade da água decai, sendo que o IQA final é classificado como Ruim, com média de 47,89. Seu resultado teve um peso maior devido à alta lâmina precipitada no período chuvoso, influenciado principalmente pela alta quantidade de coliformes.

Já o P - II (Rio Capivari) apresentou resultados semelhantes ao $\mathrm{P}-\mathrm{I}$, sendo que no período seco, de forma geral, o IQA foi classificado como Médio, fator associado com a baixa lâmina precipitada e consequentemente, com a menor quantidade de material orgânico em contato com o ponto amostral. Destaca-se que a melhor condição observada na terceira campanha $(\mathrm{IQA}=50,54)$, pode ser atribuída à época de poucas chuvas, que produziu valores de turbidez, sólidos totais e coliformes termotolerantes foram determinantes para o melhor valor de IQA. No período chuvoso, a classificação foi Ruim, podendo inferir que o escoamento superficial direto e consequentemente o carreamento de substâncias orgânicas e inorgânicas corroboraram para o aumento dos valores de sólidos, turbidez e coliformes.

Avaliando-se especialmente os pontos amostrais, observou-se que o P - III (Ingaí Luminárias) apresenta o pior índice de qualidade de água, classificado como Ruim em quase todo o período monitorado, à exceção da terceira campanha. Ressalta-se que este é o único ponto amostral localizado em área urbana e atribui-se sua classificação ao lançamento de efluentes domésticos próximos ao ponto de coleta, sendo fator fundamental para as altas concentrações de Nitrato, Fosfato, Coliformes e matéria orgânica.

Tabela 8. Valores dos parâmetros de qualidade de água e comparação com os valores máximos permitidos para Classe 2 da DN COPAM CERH 01/08 para as sub-bacias P - I, P - II e P - III.

\begin{tabular}{|c|c|c|c|c|c|c|c|c|c|}
\hline \multirow[t]{2}{*}{$\begin{array}{l}\text { Data da } \\
\text { amost. }\end{array}$} & $\begin{array}{c}\text { C.F } \\
\text { NMP/ } 100 \\
\text { mL }\end{array}$ & $\begin{array}{l}\mathrm{DBO} \\
\mathrm{mg} \mathrm{L}^{-1}\end{array}$ & $\begin{array}{l}\mathrm{PO}_{4}{ }^{3-} \\
\mathrm{mg} \mathrm{L}^{-1}\end{array}$ & $\mathrm{pH}$ & $\begin{array}{c}\text { O.D } \\
\mathrm{mg} \mathrm{L}^{-1}\end{array}$ & $\begin{array}{c}\text { S.T } \\
\text { mg L-1 }\end{array}$ & $\begin{array}{l}\mathrm{T} . \\
\left({ }^{\circ} \mathrm{C}\right)\end{array}$ & $\begin{array}{l}\text { Turb. } \\
\text { UNT }\end{array}$ & $\begin{array}{l}\mathrm{NO}_{3}^{-} \\
\text {mg.L }{ }^{-1}\end{array}$ \\
\hline & \multicolumn{9}{|c|}{ P - I (Ingaí - Minduri) } \\
\hline $10 / 04 / 15$ & $4,5 \cdot 10^{5}$ & 2,30 & 0,06 & 6,96 & 6,90 & 32,50 & 20,30 & 14,60 & 5,89 \\
\hline $29 / 07 / 15$ & 45. $10^{5}$ & 1,30 & 0,004 & 7,29 & 7,50 & 495,00 & 16,00 & 8,50 & 2,28 \\
\hline $22 / 09 / 15$ & 25. $10^{5}$ & 1,00 & 0,02 & 7,30 & 7,70 & 139,10 & 19,00 & 12,30 & 3,25 \\
\hline $26 / 10 / 15$ & 25. $10^{5}$ & 4,60 & 0,009 & 7,24 & 7,40 & 115,80 & 23,00 & 14,10 & 3,65 \\
\hline $23 / 11 / 15$ & $110.10^{5}$ & 1,00 & 0,014 & 8,46 & 7,10 & 350,00 & 19,50 & 136,60 & 3,94 \\
\hline $18 / 12 / 15$ & $140.10^{5}$ & 4,00 & 0,025 & 7,92 & 6,70 & 28,30 & 22,00 & 94,40 & 5,47 \\
\hline $22 / 01 / 16$ & $311.10^{5}$ & 3,00 & 0,055 & 8,26 & 7,80 & 105,80 & 21,80 & 48,30 & 3,94 \\
\hline \multirow[t]{2}{*}{$19 / 02 / 16$} & $2,5.10^{5}$ & 1,00 & 0,051 & 7,03 & 8,00 & 407,50 & 22,10 & 349,30 & 7,41 \\
\hline & \multicolumn{9}{|c|}{ P - II (Capivari) } \\
\hline $10 / 04 / 15$ & $4,5 \cdot 10^{5}$ & 3,00 & 0,04 & 6,60 & 6,90 & 50,00 & 21,00 & 5,50 & 12,90 \\
\hline $29 / 07 / 15$ & $0,3 \cdot 10^{5}$ & 5,00 & 0,00 & 7,30 & 7,50 & 247,50 & 15,60 & 1,40 & 2,00 \\
\hline $22 / 09 / 15$ & $2,5 \cdot 10^{5}$ & 2,30 & 0,02 & 7,10 & 7,70 & 42,50 & 16,20 & 3,90 & 3,54 \\
\hline $26 / 10 / 15$ & $200.10^{5}$ & 2,60 & 0,01 & 7,10 & 7,30 & 118,30 & 22,60 & 4,70 & 3,33 \\
\hline $23 / 11 / 15$ & 140. $10^{5}$ & 3,00 & 0,01 & 8,10 & 6,90 & 358,00 & 22,00 & 258,30 & 7,83 \\
\hline $18 / 12 / 15$ & $110.10^{5}$ & 2,60 & 0,02 & 8,10 & 6,50 & 17,50 & 21,80 & 200,60 & 7,69 \\
\hline $22 / 01 / 16$ & $300.10^{5}$ & 2,00 & 0,03 & 8,20 & 7,60 & 76,60 & 20,90 & 25,70 & 5,19 \\
\hline \multirow[t]{2}{*}{$19 / 02 / 16$} & $4,0.10^{5}$ & 2,00 & 0,07 & 6,80 & 7,70 & 458,30 & 20,50 & 111,40 & 3,81 \\
\hline & \multicolumn{9}{|c|}{ P - III (Ingaí - Luminárias) } \\
\hline $26 / 05 / 15$ & $20.10^{5}$ & 3,30 & 0,233 & 7,37 & 7,00 & 343,30 & 21,00 & 10,00 & 9,91 \\
\hline $29 / 07 / 15$ & $25.10^{5}$ & 5,00 & 0,009 & 7,22 & 7,80 & 5,00 & 16,70 & 5,20 & 6,30 \\
\hline $22 / 09 / 15$ & $25.10^{5}$ & 2,00 & 0,012 & 7,05 & 7,50 & 46,60 & 19,60 & 15,40 & 3,53 \\
\hline $26 / 10 / 15$ & $20.10^{5}$ & 3,00 & 0,017 & 7,14 & 7,30 & 153,30 & 23,50 & 8,40 & 3,81 \\
\hline $23 / 11 / 15$ & $140.10^{5}$ & 2,30 & 0,023 & 7,99 & 7,20 & 525,00 & 21,40 & 129,00 & 3,67 \\
\hline $18 / 12 / 15$ & 25. $10^{5}$ & 3,00 & 0,042 & 8,08 & 6,40 & 27,50 & 22,30 & 128,00 & 4,86 \\
\hline $22 / 01 / 16$ & $110.10^{5}$ & 1,60 & 0,031 & 8,07 & 8,00 & 136,60 & 22,20 & 76,80 & 3,25 \\
\hline $19 / 02 / 16$ & $2,5 \cdot 10^{5}$ & 3,00 & 0,016 & 6,5 & 7,80 & 565,00 & 23,10 & 156,30 & 7,83 \\
\hline VMP & $\leq 1000$ & $\leq 5$ & $\leq 0,1$ & 6 e 9 & $>5$ & $\leq 500$ & - & 100 & $\leq 10$ \\
\hline
\end{tabular}

VMP: Valor máximo permitido. Em negrito, estão destacados os valores que suplantaram o VMP da classe 2 da DN COPAM CERH 01/08. 
Tabela 9. Valores dos parâmetros de qualidade de água e comparação com os valores máximos permitidos para Classe 2 da DN COPAM CERH 01/08 para as sub-bacias P - IV, P - V e P - VI.

\begin{tabular}{|c|c|c|c|c|c|c|c|c|c|}
\hline \multirow[t]{2}{*}{ Data da amost. } & $\begin{array}{c}\text { C.F } \\
\mathrm{NMP} / 100 \mathrm{~mL}\end{array}$ & $\begin{array}{c}\mathrm{DBO} \\
\mathrm{mg} \mathrm{L^{- }} \\
1\end{array}$ & $\begin{array}{l}\mathrm{PO}_{4}^{3-} \\
\mathrm{mg} \mathrm{L}_{1}^{3-}\end{array}$ & $\mathrm{pH}$ & $\begin{array}{c}\text { O.D } \\
\text { mg } \\
L^{-1} \\
\end{array}$ & $\begin{array}{c}\text { S.T } \\
\text { mg L L }\end{array}$ & $\begin{array}{l}\text { Temp } \\
\left({ }^{\circ} \mathrm{C}\right)\end{array}$ & $\begin{array}{l}\text { Turb } \\
\text { UNT }\end{array}$ & $\begin{array}{l}\mathrm{NO}_{3}{ }^{-} \\
\mathrm{mg} \mathrm{L}_{1}^{-}\end{array}$ \\
\hline & \multicolumn{9}{|c|}{ P - IV (Mortes) } \\
\hline $28 / 04 / 15$ & $2,5.10^{5}$ & 3,30 & 0,02 & 7,18 & 7,39 & 91,67 & 21,00 & 24,12 & 8,94 \\
\hline $22 / 07 / 15$ & $25.10^{5}$ & 4,60 & 0,014 & 6,98 & 8,80 & 193,00 & 16,70 & 15,20 & 2,00 \\
\hline $15 / 09 / 15$ & $25.10^{5}$ & 1,60 & 0,006 & 7,18 & 8,00 & 175,00 & 19,68 & 38,00 & 7,97 \\
\hline $19 / 10 / 15$ & $9,5 \cdot 10^{5}$ & 2,67 & 0,008 & 7,32 & 7,20 & 191,60 & 23,54 & 10,08 & 4,92 \\
\hline $16 / 11 / 15$ & $0,4 \cdot 10^{5}$ & 1,30 & 0,016 & 7,59 & 6,76 & 166,00 & 24,40 & 153,00 & 9,77 \\
\hline $14 / 12 / 15$ & $25.10^{5}$ & 4,00 & 0,035 & 8,15 & 7,10 & 1114,00 & 23,81 & 512,00 & 3,20 \\
\hline $19 / 01 / 16$ & 25. $10^{5}$ & 1,00 & 0,01 & 7,61 & 7,30 & 357,50 & 21,36 & 129,60 & 8,38 \\
\hline \multirow[t]{2}{*}{$17 / 02 / 16$} & $4,0.10^{5}$ & 1,00 & 0,063 & 7,49 & 7,30 & 401,60 & 23,30 & 192,00 & 4,08 \\
\hline & \multicolumn{9}{|c|}{$\mathbf{P}-\mathrm{V}$ (Peixe) } \\
\hline $22 / 07 / 15$ & $2,5 \cdot 10^{5}$ & 3,00 & 0,02 & 7,14 & 8,00 & 175,00 & 16,70 & 12,63 & 2,28 \\
\hline $15 / 09 / 15$ & $0,3 \cdot 10^{5}$ & 1,00 & 0,014 & 7,24 & 7,40 & 179,10 & 23,00 & 40,70 & 3,53 \\
\hline $19 / 10 / 15$ & $0,6 \cdot 10^{5}$ & 5,00 & 0,017 & 7,44 & 7,10 & 195,80 & 26,20 & 8,91 & 4,50 \\
\hline $16 / 11 / 15$ & $3,5 \cdot 10^{5}$ & 3,00 & 0,014 & 7,51 & 7,90 & 350,00 & 22,00 & 371,00 & 8,38 \\
\hline $14 / 12 / 15$ & $0,9 \cdot 10^{5}$ & 1,60 & 0,003 & 8,15 & 7,70 & 12540 & 23,80 & 728,00 & 3,81 \\
\hline $19 / 01 / 16$ & $1,4 \cdot 10^{5}$ & 1,60 & 0,026 & 7,93 & 7,80 & 287,50 & 21,31 & 122,00 & 2,00 \\
\hline \multirow[t]{2}{*}{$17 / 02 / 16$} & $1,1 \cdot 10^{5}$ & 1,00 & 0,059 & 6,66 & 7,00 & 167,50 & 23,66 & 124,80 & 1,73 \\
\hline & \multicolumn{9}{|c|}{ P - VI (Ribeirão dos Tabuões) } \\
\hline $14 / 05 / 15$ & $0,2.10^{5}$ & 1,30 & 0,148 & 7,20 & 7,40 & 173,30 & 19,00 & 60,00 & 9,56 \\
\hline $22 / 07 / 15$ & $2,5 \cdot 10^{5}$ & 2,60 & 0,176 & 7,06 & 8,60 & 180,80 & 24,60 & 19,20 & 10,88 \\
\hline $15 / 09 / 15$ & $2,5 \cdot 10^{5}$ & 1,00 & 0,023 & 7,29 & 7,40 & 151,60 & 29,28 & 46,60 & 3,53 \\
\hline $19 / 10 / 15$ & $2,5 \cdot 10^{5}$ & 4,60 & 0,055 & 7,46 & 6,50 & 182,50 & 31,40 & 9,96 & 5,05 \\
\hline $16 / 11 / 15$ & $9,5 \cdot 10^{5}$ & 3,00 & 0,012 & 7,58 & 7,40 & 100,00 & 25,00 & 153,60 & 9,08 \\
\hline $14 / 12 / 15$ & $7,5 \cdot 10^{5}$ & 2,60 & 0,03 & 8,29 & 7,93 & 1069,00 & 27,20 & 512,00 & 2,14 \\
\hline $19 / 01 / 16$ & $115.10^{5}$ & 2,30 & 0,026 & 7,79 & 7,50 & 310,80 & 23,56 & 114,60 & 1,73 \\
\hline $17 / 02 / 16$ & $4,0.10^{5}$ & 1,00 & 0,06 & 7,03 & 7,00 & 165,80 & 28,13 & 73,06 & 0,20 \\
\hline VMP & $\leq 1000$ & $\leq 5$ & $\leq 0,1$ & 6 e 9 & $>5$ & $\leq 500$ & - & 100 & $\leq 10$ \\
\hline
\end{tabular}

De uma maneira geral, observou-se que a sazonalidade da chuva influenciou a classificação do IQA nos três pontos amostrais da sub-bacia hidrográfica Capivari, localizada na UPGRH GD1, evidenciando uma qualidade das águas pela faixa médio no período de inverno (com exceção do ponto amostral Ingaí - Luminárias) quando as precipitações são menores. Já o período de chuvas, foi observado um IQA com qualidade inferior, devido ao carreamento de partículas pelo escoamento superficial direto, afetando a qualidade da água.

Na Figura 4 estão apresentados os valores de IQA e a correspondente classificação para as avaliações realizadas nas seções de controle monitoradas na Bacia hidrográfica do Rio das Mortes.

$\mathrm{O}$ ponto amostral $\mathrm{P}$ - IV, localizado nas proximidades de Conceição da Barra de Minas, apresentou seus melhores resultados de IQA na segunda e quarta campanhas, respectivamente, e foram classificados como Médio, podendo estar associado às baixas precipitações e menores concentrações de nitrato em relação as outras campanhas do período seco. Nas demais campanhas o IQA foi classificado como Ruim.

Já no P - V localizado nas proximidades de São Tiago o IQA, no período seco, foi classificado como Médio, fator associado às baixas precipitações ocorridas antes da avaliação. No período de altas precipitações, o IQA foi classificado como Ruim, sendo que as variáveis determinantes para este resultado foram os altos valores de sólidos totais, turbidez e coliformes, como carreamento de partículas sólidas e fezes de animais, devido à presença de gado no entorno da bacia, e, por ser uma área com grande predominância de pastagem e ausência da mata ciliar, contribuindo para a degradação do curso d'água.

No ponto amostral P - VI, não se verificou oscilação em relação à classificação, sendo enquadrados nos períodos de estiagem e chuvoso como Ruim. A classificação justifica-se pela ausência de mata ciliar, o pisoteio de animais próximo às margens do curso d'agua e o assoreamento nítido. Estes foram fatores fundamentais para as elevadas concentrações de coliformes, nitrato, sólidos totais e turbidez e 
determinantes para a classificação do IQA. Destaca-se ainda, que os piores valores foram observados em época chuvosa (quinta, sexta e sétima coletas), sendo que os parâmetros que mais prejudicaram o IQA foram as altas concentrações de sólidos totais, turbidez e o aumento de coliformes termotolerantes.

A qualidade da água na sub-bacia hidrográfica Mortes, nos três pontos amostrais, apresentaram IQA enquadrado como Ruim, sendo o ponto amostral P VI (Ribeirão dos Tabuões) o de pior qualidade. A classificação do IQA como Ruim pode ser explicada devido ao manejo incorreto dos solos, o assoreamento dos cursos d'água, ausência de mata ciliar, o contato direto de gado com as margens e o despejo incorreto de efluentes.

\section{CONCLUSÃO}

Durante o monitoramento, as características de cada região como o uso do solo influenciaram de alguma forma a qualidade da água nas sub-bacias analisadas.

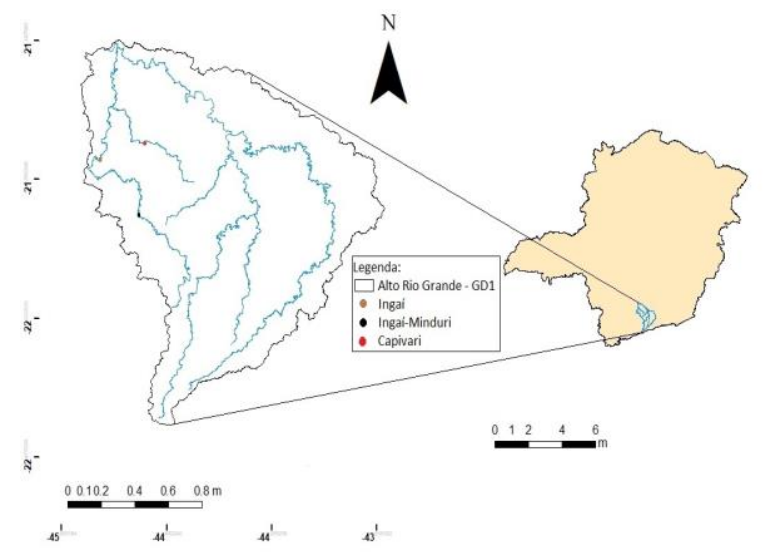

Figura 1. Localização de estudo na bacia do Alto Rio Grande (GD1).
O excesso do fósforo nos cursos d'água, oriundos de adubação química e também do lançamento de esgotos não tratados foram impactantes, afetando de forma significativa as sub-bacias monitoradas, caracterizando os graus de trofia como Hipereutrófico;

A influência da sazonalidade da chuva, no geral, modifica a qualidade da água, aumentando os sólidos totais, turbidez e principalmente os coliformes termotolerantes, que foram determinantes nos resultados encontrados.

O IQA, no geral, teve classificações finais como ruins em todos os pontos de monitoramento, devido as atividades entorno da bacia, como a pecuária, irrigação e as poluições pontuais.

A intervenção na bacia, com tratamento de águas residuárias antes do seu lançamento, e controle do uso e ocupação do solo, são medidas necessárias para melhoria da qualidade da água dos rios avaliados.

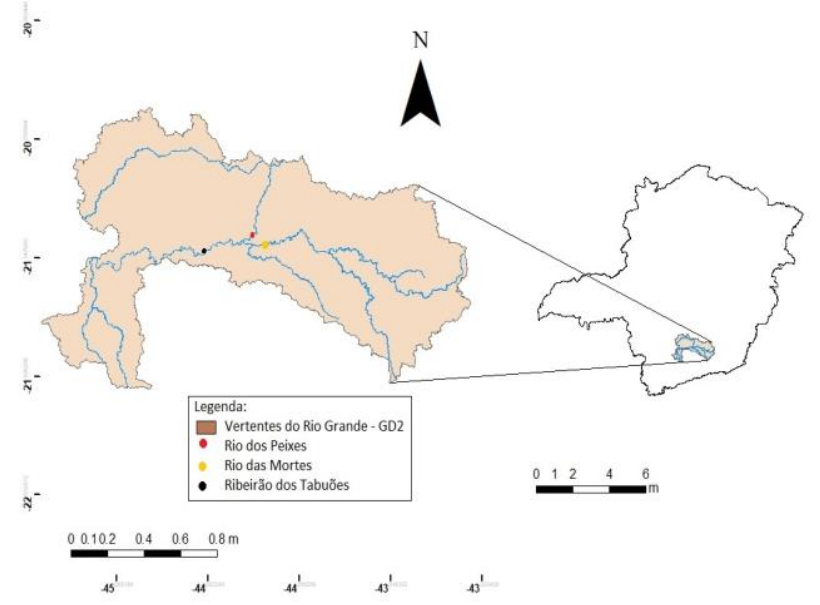

Figura 2. Localização de estudo na sub-bacia Vertentes do Rio Grande (GD2) 


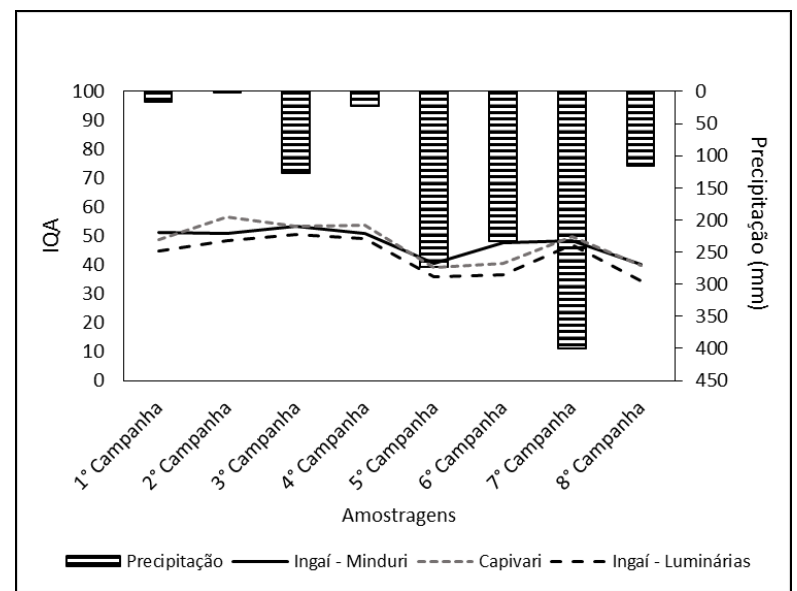

Figura 3. IQA e lâmina precipitada na sub-bacia Hidrográfica Capivari durante o período monitorado

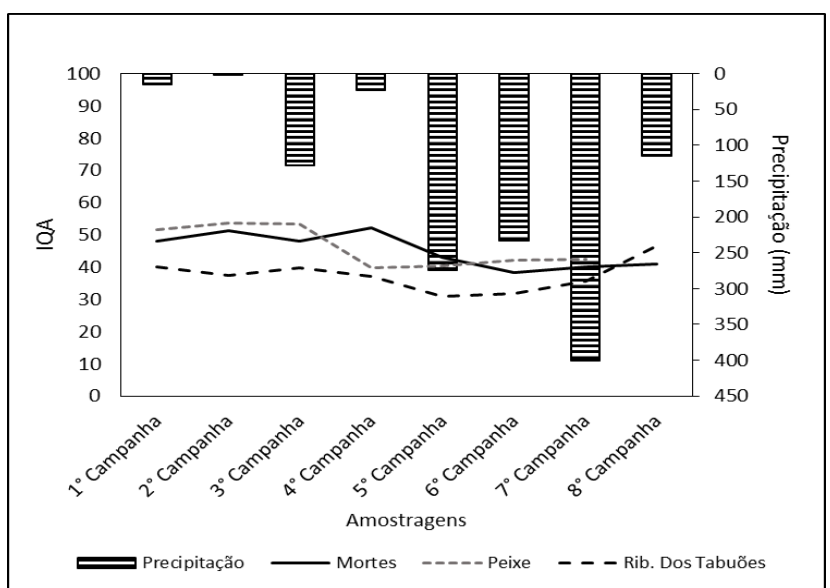

Figura 4. IQA e lâmina precipitada na sub-bacia Hidrográfica Mortes durante o período monitorado.

\section{REFERÊNCIAS}

AMERICAN Public Health Association. Standard Methods For The Examination of Water and W astewater. 22 ed. Washington: APHA, 2012.

ANDRADE, E. M.; PALÁCIO, H.A.Q.; CRISÓSTOMO, L. A.; SOUZA, I. H.; TEIXEIRA, A. S. . Índice de qualidade de água, uma proposta para o vale do rio Trussu, Ceará. Revista Ciência Agronômica, v. 36, n. 2, p. 135-142, 2005.

\section{COMPANHIA DE TECNOLOGIA DE} SANEAMENTO AMBIENTAL. Guia nacional de coleta e preservação de amostras: água, sedimento, comunidades aquáticas e percolados líquidos. São Paulo: CETESB, 2011.

DANTAS, A. A. A.; CARVALHO, L. G.; FERREIRA, E. Classificação e tendências climáticas em Lavras, MG. Cienc. Agrotec, Lavras, v. 31, n. 6, p. 1862-1866, nov./dez., 2007.

DE AZEVEDO LOPES, F. W.; MAGALHÃES JR., A. P. M. Influência das condições naturais de $\mathrm{pH}$ sobre o índice de qualidade das águas (IQA) na bacia do Ribeirão de Carrancas. Geografias, v. 6, n. 2, p. 134147, 2010.
EMBRAPA. Empresa Brasileira De Pesquisa Agropecuária . Agricultura e Qualidade de Agna: Contaminação da Água por Nitrato. 2002. 28 p.

FERREIRA, K, C, D; LOPES, F, B; ANDRADE, E, M; MEIRELES, A, C, M; SILVA, G, S. Adaptação do índice de qualidade de água da National Sanitation Foundation ao semiárido brasileiro. Revista Ciência Agronômica, v. 46, n. 2, p. 277-286, abr-jun, 2015.

FIA, R.; MATOS, A. T.; CORADI, P. C.; RAMIREZ, O. P. Estado Trófico da água na bacia hidrográfica da Lagoa Mirim, RS, Brasil. Revista Ambiente \& Agua - An Interdisciplinary Journal of Applied Sciente: v. 4, n. 1, 2009.

INSTITUTO MINEIRO DE GESTÃO DAS ÁGUAS - IGAM. Índice de Qualidade de água. Disponível em:

$<$ http://portalpnqa.ana.gov.br/indicadores-indiceaguas.aspx>. Acesso em: 18 abr. 2016.

LAMPARELLI, M. C. Grau de trofia em corpos d'água do estado de São Paulo: avaliação dos métodos de monitoramento. 2004. São Paulo. Tese. 235 p. (Doutorado) Universidade de São Paulo, 2004. 
LIMA, R, N, S; RIBEIRO, C, B, M; BARBOSA, C, C, F; FILHO, O, C, R. Estudo da poluição pontual e difusa na bacia de contribuição do reservatório da Usina Hidrelétrica do Funil utilizando modelagem espacialmente distribuída em Sistema de Informação Geográfica. 2016. Eng Sanit Ambient, v. 21, n. 1, p. 139-150

LOPES, F. B.; TEIXEIRA, A. S.; ANDRADE, E. M.; AQUINO, D. N.; ARAÚJO, L. F. P. Mapa da qualidade das águas do rio Acaraú, pelo emprego do IQA e Geoprocessamento. Revista Ciência Agronômica, v. 39, n. 3, p. 392-402, 2008.

MARQUES, M. K.; FERNANDES, B. L.; GUILHERME, D. D.; OLINDA, R. G.; LIMA, J. T. A. X. Pescado contaminado por Escherichia coli na área urbana do rio Apodi-Mossoró, Rio Grande do Norte. Revista Centauro, v.2, n.2, p.50-56, 2011.

MINAS GERAIS. Secretaria de Estado de Meio Ambiente e Desenvolvimento Sustentável. Zoneamento ecoloógico - econômico do Estado de Minas Gerais - ZEEMG. Belo Horizonte, 2008. Disponível em:

$<$ http://www.zee.gov.br/pdf/componentes_geofisic o_biotico/5recursos_h\%C3\%ADdricos.pdf $>$. Acesso em: 25 jan. 2016.

MINAS GERAIS. Deliberação normativa conjunta COPAM/CERH-MG, no. 01, de 05 de maio de 2008. Disponível em:

<http://www.siam.mg.gov.br/sla/download.pdf?idN orma $=8151>$. Acesso em: 12 ago. 2015.

PINTO, D. B. F.; SILVA, A. M.; MELLO, C. R.; COELHO, G. Qualidade da água do Ribeirão Lavrinha na região Alto Rio Grande - MG, Brasil. Ciênc. agrotec. v. 33, n. 4, p. 1145-1152, 2009.

POLETO, C.; CARVALHO, S. L. Avaliação da influência da degradação do solo de uma microbacia bidrográfica na qualidade da água do Córrego do Ipê, municipio de Ilha Solteira-SP.

Disponível em:

<http://cemac-

ufla.com.br/AnaisTrabVoluntários.htm $>$ Acesso em: 12 mar. 2016.

SÁNCHEZ, E.; COLMENAREJO, M. F.; VICENT, J.; RUBIO, A.; GARCÍA, M. G.; TRAVIESO, L.; BORJA, R. Use of the water quality index and dissolved oxygen deficit as simple indicators of watersheds pollution. Ecological Indicators, v. 7, n. 2, p. 315-328, 2007.
SCOLFORO, J. R. S.; CARVALHO, L. M. T. Mapeamento da flora nativa e dos reflorestamentos de Minas Gerais. Lavras: UFLA, 2006. 288 p. v.1.

VON SPERLING, M. Introdução à qualidade das águas e ao tratamento de esgotos. v.1, 4. ed. Belo Horizonte: UFMG, 2014. 452 p. 